M. C. Reis, et al., Int. J. Comp. Meth. and Exp. Meas., Vol. 6, No. 1 (2018) 35-45

\title{
NUMERICAL SIMULATIONS FOR HOMOGENEOUS NUCLEATION OF CALCIUM CARBONATE IN CONCENTRATED ELECTROLYTE SOLUTIONS
}

\author{
MARTINA COSTA REIS ${ }^{1}$, MARIA DE FÁTIMA BRITO SOUSA ${ }^{1}$, FALAH ALOBAID $^{2}$, \\ CELSO APARECIDO BERTRAN ${ }^{1} \&$ YONGQI WANG ${ }^{3}$ \\ ${ }^{1}$ Institute of Chemistry, University of Campinas-UNICAMP, Brazil. \\ ${ }^{2}$ Institute of Energy Systems and Technology, Technische Universität Darmstadt, Germany. \\ ${ }^{3}$ Institute of Fluid Dynamics, Technische Universität Darmstadt, Germany.
}

\begin{abstract}
Homogeneous nucleation of calcium carbonate is a common phenomenon in nature, which has attracted attention from researchers due to its importance in biomineralization processes, climatic changes and incrustations in pipelines. In this work, by using a numerical scheme based on SIMPLE algorithm, 3D numerical simulations are performed for the homogeneous nucleation of calcium carbonate in highly concentrated electrolyte solutions. For this purpose, one couples the Eulerian equations for multiphase flows to the discretized population balance equations, so that the resulting system of non-linear partial differential equations accounts for the mass transfer and changes in the particles size during the precipitation reaction. In order to validate the proposed model, experimental measurements of $\mathrm{pH}$ versus time and particles size distribution are compared with theoretical data. The remarkable agreement observed between the theoretical and experimental results indicates that the employed approach can be successfully used in studies of homogeneous nucleation of other sparingly soluble mineral salts.

Keywords: calcium carbonate nucleation, eulerian formulation, population balance equation, volumetric precipitation experiments.
\end{abstract}

\section{INTRODUCTION}

Nucleation of calcium carbonate in aqueous solutions is a topic that has attracted attention from researchers in a variety of fields due to its importance in biomineralization processes, formation of coral reefs in oceans, and climatic changes. Of significant interest is also the study of calcium carbonate precipitation in concentrated electrolyte solutions since crystallization of $\mathrm{CaCO}_{3}(\mathrm{~s})$ is the most common and important source of mineral scales in petroleum industries $[1,2]$.

In processes of oil recovery by water flooding, mixing of two water solutions said to be incompatible occurs: the seawater that is injected into reservoirs during the water flooding stage, and the produced water that is the seawater extracted together with oil and gas. While the injected water is rich in $\mathrm{Ca}^{2+}(\mathrm{aq}), \mathrm{Mg}^{2+}(\mathrm{aq}), \mathrm{Sr}^{2+}(\mathrm{aq})$, and $\mathrm{Ba}^{2+}(\mathrm{aq})$ ions, produced water contains elevated concentrations of $\mathrm{CO}_{3}^{2-}(\mathrm{aq})$ ions as a consequence of alteration of sedimentary rocks on the sea floor over geological time. Then, whenever these incompatible waters are in contact, and the state of the fluid as a whole is perturbed by an abrupt change of pressure, temperature, $\mathrm{pH}$ or even by a change of the flow regime, the solubility limit of $\mathrm{CaCO}_{3}(\mathrm{~s})$ is exceeded, and the salt precipitates, according to eqn (1):

$$
\mathrm{Ca}^{2+}(\mathrm{aq})+\mathrm{CO}_{3}^{2-}(\mathrm{aq}) \rightleftharpoons \mathrm{CaCO}_{3}(\mathrm{~s})
$$

Therefore, the fluid that streams along the wellbore consists of a multiphase mixture, where solid particles of calcium carbonate coexist with two miscible aqueous solutions of completely different chemical compositions. This fluid flow presents a very complex thermodynamic behavior as it depends on the seawater composition, temperature, pressure, $\mathrm{pH}$, oil pipelines 
dimensions, etc. Moreover, the possibility of convective turbulence in pipelines can catalyze scale deposition, complicating the thermodynamic behavior of the multiphase mixture.

Although many practical studies $[3,4]$ about removal and prevention of calcium carbonate scales have been developed in laboratories during the last years, the thermodynamics of the process of calcium carbonate precipitation in concentrated electrolyte solutions is not well-understood yet. As a matter of fact, most of the information available about mineral scales in saltwater mixtures was empirically obtained. In addition, the few theoretical models $[5,6]$ about crystallization of calcium carbonate in electrolyte solutions are based on the foundations of classical thermodynamics, which has been recognized as unsatisfactory due to its limited scope.

In view of this, this manuscript aims to study the thermodynamics of the process of calcium carbonate precipitation in concentrated electrolyte solutions. By modeling a reactive solid-liquid mixture according to the Eulerian formulation for multiphase flows, emphasis is put on the interfacial transport of mass, which is closely related to the precipitation kinetics and the evolution of particles size. Furthermore, numerical simulations for homogeneous nucleation of calcium carbonate in concentrated electrolyte solutions are performed, and the results are compared with those obtained from volumetric precipitation experiments. The good agreement between the theoretical and experimental results shows that the numerical simulations reproduce the essential characteristics of the process of calcium carbonate precipitation in concentrated electrolyte solutions.

\section{MODEL EQUATIONS}

Likewise single-phase flows, phenomenological models for solid-liquid mixtures are also formulated in terms of field equations and constitutive laws. Nevertheless, the physical principles that govern the thermodynamics of such multiphase mixtures are definitely more complex due to the presence of multiple, deformable and moving interfaces, and the possibility of interfacial mass, momentum and energy transfers. This fact has motivated the development of models based on averaging methods that provide a continuum approach for multiphase flows, by eliminating local instant fluctuations of certain physical quantities.

Among the averaging procedures described in the literature, Eulerian spatial averaging theory is one of the most used methods in the modeling of multiphase mixtures. According to this method [7], the phases are treated separately, so each phase has its own governing balance equations and constitutive laws. However, since each phase does not evolve independently, interfacial interaction terms appear in the balance equations in order to couple the exchange of physical properties between the phases.

For a reactive solid-liquid mixture whose liquid phase is an electrolyte solution, the balance equations of mass and linear momentum are postulated as,

$$
\begin{gathered}
\rho_{1} \frac{\partial \alpha_{1}}{\partial t}+\rho_{1} \operatorname{div}\left(\alpha_{1} \mathbf{v}_{1}\right)-a \dot{m}_{1}=0 \\
\rho_{2} \frac{\partial \alpha_{2}}{\partial t}+\rho_{2} \operatorname{div}\left(\alpha_{2} \mathbf{v}_{2}\right)-a \dot{m}_{2}=0 \\
\rho_{1} \frac{\partial \alpha_{1} \mathbf{v}_{1}}{\partial t}+\rho_{1} \operatorname{div}\left(\alpha_{1} \mathbf{v}_{1} \otimes \mathbf{v}_{1}\right)+\alpha_{1} \nabla p_{1}-\operatorname{div} \boldsymbol{T}_{1}-\alpha_{1} \rho_{1} \mathbf{g}+c_{12}\left(\mathbf{v}_{2}-\mathbf{v}_{1}\right)+a \dot{m}_{1} \mathbf{v}_{1}=0 \\
\rho_{2} \frac{\partial \alpha_{2} \mathbf{v}_{2}}{\partial t}+\rho_{2} \operatorname{div}\left(\alpha_{2} \mathbf{v}_{2} \otimes \mathbf{v}_{2}\right)+\alpha_{2} \nabla p_{1}+\nabla p_{2}-\operatorname{div} \boldsymbol{T}_{2}-\alpha_{2} \rho_{2} \mathbf{g}-c_{12}\left(\mathbf{v}_{2}-\mathbf{v}_{1}\right)+a \dot{m}_{2} \mathbf{v}_{2}=0
\end{gathered}
$$


where the indexes $k=1$ and $k=2$, respectively, refer to quantities of the liquid and solid phases. Moreover, in the above equations, $\alpha_{k}$ stands for the volume fraction of phase $k$, such that $\alpha_{1}+\alpha_{2}=1, \rho_{k}$ is the true mass density, $\dot{m}_{k}$ is the mass transfer rate per unit area of interface, such that $\dot{m}_{k}$ is subject to the constraint $\dot{m}_{1}+\dot{m}_{2}=0, a$ is the surface area of the solid-liquid interface per unit volume of dispersion, $\mathbf{v}_{k}$ is the partial velocity, $p_{1}$ is the hydrostatic pressure, $p_{2}$ is the solid pressure, $\boldsymbol{T}_{k}$ is the stress tensor, $\mathbf{g}$ is the gravity field and $c_{12}$ is a coefficient related to the drag force.

Eqns (2)-(5) are balance equations that any reactive solid-liquid mixture should satisfy. However, the particularities of system may be considered, if proper constitutive equations for $\dot{m}_{k}, \boldsymbol{T}_{\mathrm{k}}, p_{2}$ and $c_{12}$ are introduced into the above system of equations. For this purpose, assume that the liquid phase contains dissolved $\mathrm{Ca}^{2+}(\mathrm{aq}), \mathrm{Na}^{+}(\mathrm{aq}), \mathrm{CO}_{3}^{2-}(\mathrm{aq})$ and $\mathrm{Cl}^{-}(\mathrm{aq})$ ions. This is the simplest chemical composition in which precipitation of calcium carbonate in high strength ionic solutions may occur. Furthermore, consider that the concentrations of $\mathrm{Na}^{+}(\mathrm{aq})$ and $\mathrm{Cl}^{-}$(aq) ions are much larger than the other ions, so that they are in large part responsible for the high ionic strength of solution. Under such circumstances, sodium and chloride ions behave as spectator ions, and $\dot{m}_{1}$ only depends on the concentrations of $\mathrm{Ca}^{2+}(\mathrm{aq})$ and $\mathrm{CO}_{3}^{2-}$ (aq).

As a matter of fact, constitutive equations for mass transfer terms are frequently troublesome because they require knowledge of the reaction kinetics and some physico-chemical parameters that are not always available. Nevertheless, constitutive equations for mass transfer terms of heterogeneous chemical reactions can be promptly proposed, if one regards the precipitation of particles as the final result of an assembly of phenomena, namely nucleation, breakage, aggregation and growth. With this approach [8], one not only gains a phenomenological insight into the precipitation chemical reaction, but also information about the temporal evolution of particles size during the reaction.

Then, consider the population balance equation in its discretized form [9],

$$
\frac{\partial \varphi_{i}}{\partial t}+\rho_{2} \operatorname{div}\left(\mathrm{v}_{2} \varphi_{i}\right)+V_{i}\left(\frac{G_{i-1} N_{i-1}}{V_{i}-V_{i-1}}-\frac{G_{i} N_{i}}{V_{i+1}-V_{i}}\right)+\delta_{i 0} V_{0} B_{0}=0 \quad i=0, \ldots, J-1,
$$

where $\varphi_{i}$ is the volume fraction of particles with volume $V_{i}, N_{i}$ is the local number of particles per unit volume of dispersion, $G_{i}$ is the growth rate of particles, $B_{0}$ is the nucleation rate of particles, and $\delta_{i 0}$ is the Kronecker delta. Furthermore, $J$ is a positive integer and designates the number of discrete size classes of the particulate phase, such that $V_{0}$ is the volume associated with the particles of smallest volume that belong to the discrete size class $l_{J-1}$, whereas $V_{J-1}$ is the volume related to the particles of largest volume that belong to the discrete size class $l_{0}$. Since homogeneous nucleation of $\mathrm{CaCO}_{3}(\mathrm{~s})$ is, according to the classical theory of nucleation [10], a process governed mainly by the supersaturation ratio $S$, one expresses the nucleation rate $B_{0}$ by,

$$
B_{0}=A \exp \left[-\frac{\beta \sigma^{3} \vartheta^{3}}{2.30 k_{B}^{3} T^{3}(\log S)^{2}}\right],
$$

where $\beta$ is the geometrical shape factor, $\sigma$ is the surface energy, $\vartheta$ is the molecular volume of calcium carbonate, $k_{B}$ is the Boltzmann constant, $T$ is the absolute temperature, $S$ is the supersaturation ratio, and $A$ is a pre-exponential factor related to the energy barrier that ions in solution must overcome in order to form the critical nucleus. Such a pre-exponential factor may be approximated as a constant, if one considers only nucleation of pure ionic substances under isothermal conditions, 


$$
A=\frac{D}{\delta^{5} S^{5 / 3}},
$$

where $D$ is the diffusion coefficient for calcium carbonate, and $\delta$ is the interionic distance between $\mathrm{Ca}^{2+}(\mathrm{aq})$ and $\mathrm{CO}_{3}^{2-}(\mathrm{aq})$ ions. On the other hand, based on empirical data [11] for unseeded nucleation of calcite and vaterite in solutions of high ionic strength, the kinetics of growth of $\mathrm{CaCO}_{3}$ (s) can be described by,

$$
G_{i}=k(S-1)^{2}
$$

where $k$ is a constant given by,

$$
\log \left(k / \mathrm{nm} \mathrm{s}^{-1}\right)=-0.275+\left[\frac{0.228\left(I / \mathrm{mol} \mathrm{L}^{-1}\right)^{1 / 2}}{1+\left(I / \mathrm{mol} \mathrm{L}^{-1}\right)^{1 / 2}}-0.300\left(I / \mathrm{mol} \mathrm{L}^{-1}\right)\right],
$$

and $I$ is the ionic strength of solution. Hence, since summation of eqn (6) over all discrete size classes leads to the volume fraction balance of the solid phase, it follows that the mass transfer rate may be given by the sum of nucleation and growth rates,

$$
\delta \dot{m}_{2}=\rho_{2} \sum_{i=0}^{J-1} V_{i}\left(\frac{G_{i-1} N_{i-1}}{V_{i}-V_{i-1}}-\frac{G_{i} N_{i}}{V_{i+1}-V_{i}}\right)+\rho_{2} V_{0} B_{0} .
$$

For the remaining constitutive quantities of the system of non-linear partial differential equations, phenomenological laws can be easily postulated, if one recalls certain well-established constitutive models available in the literature. By regarding the liquid phase as a Newtonian fluid, bulk viscosity is neglected and the stress tensor is given by $\boldsymbol{T}_{1}=2 \alpha_{1} \mu_{1} \boldsymbol{D}_{1}$, where $\mu_{1}$ is the dynamic viscosity, and $\boldsymbol{D}_{1}$ is the stretching tensor. Moreover, if one regards the contact forces between particles as negligible, then $\boldsymbol{T}_{2}$ may be ignored in eqn (5). In turn, the drag force and the solid pressure in a solid dispersion could be described according to the model proposed by Syamlal and O'Brien [12], where the solid-liquid mixture is treated as an incompressible fluid at a certain critical void fraction.

As previously pointed out, the liquid phase is a solution containing different ions that appear as a result of the dissociation of $\mathrm{Na}_{2} \mathrm{CO}_{3}(\mathrm{aq}), \mathrm{NaCl}(\mathrm{aq})$ and $\mathrm{CaCl}_{2}(\mathrm{aq})$ in water. In view of this, it would be convenient to express the volume fraction balance of the liquid phase in terms of the volume fraction of each ionic compound $v$ present in solution. For this purpose, assume that (i) the volume occupied by each ionic compound in solution represents only a part of the volume taken by the whole solution, and (ii) the dynamics of each ionic compound is nearly equal to the dynamics of solvent. Therefore, one may relate the quantities of the electrolyte solution to those of its constituents by,

$$
\alpha_{1}=\sum_{v=1}^{3} \alpha_{1}^{v}, \quad \rho_{1} \alpha_{1} \mathrm{v}_{1}=\sum_{v=1}^{3} \rho_{1}^{v} \alpha_{1}^{v} \mathrm{v}_{1}^{v}, \quad \dot{m}_{1}=\sum_{v=1}^{3} \dot{m}_{1}^{v},
$$

whence it is straightforward that

$$
\rho_{1}^{v} \frac{\partial \alpha_{1}^{v}}{\partial t}+\rho_{1}^{v} \operatorname{div}\left(\alpha_{1}^{v} \mathrm{v}_{1}\right)-a \dot{m}_{1}^{v}=0
$$

where $\alpha_{1}^{v}$ is the volume fraction of an ionic compound $v$ in the liquid phase, $\rho_{1}^{v}$ is the true density of an ionic compound, and $\dot{m}_{1}^{v}$ is the mass transfer rate of an ionic compound $v$ in the liquid phase. 


\section{EXPERIMENTAL PROCEDURE}

The adopted experimental procedure to study homogeneous nucleation of calcium carbonate in concentrated electrolyte solutions is based on volumetric precipitation experiments, as described by Sousa and Bertran [4]. According to this method, an automatic injector Titrino Plus 848 (Metrohm) is used to dispense a dilute solution of sodium carbonate $\left(0.020 \mathrm{~mol} \mathrm{~L}^{-1}\right)$ into the dispensing unit of a particle size analyzer Mastersize 2000 (Malvern) that contains a mixture of $125.00 \mathrm{~mL}$ of calcium chloride $\left(0.45 \mathrm{~mol} \mathrm{~L}^{-1}\right)$ and sodium chloride (3.42 $\mathrm{mol} \mathrm{L}^{-1}$ ). In order to follow the changes of $\mathrm{pH}$ during the experiment, a combined glass $\mathrm{Ag} / \mathrm{AgCl}$ electrode (Metrohm) is coupled to the automatic injector. Then, the solution of sodium carbonate is added to the mixture of $\mathrm{NaCl}(\mathrm{aq})$ and $\mathrm{CaCl}_{2}(\mathrm{aq})$ at a rate of $0.5 \mathrm{~mL} \mathrm{~min}^{-1}$ until a critical point, where the mixture $\mathrm{pH}$ reaches its maximum value and precipitation of $\mathrm{CaCO}_{3}(\mathrm{~s})$ begins. At this point, addition of sodium carbonate is suspended, but measurements of $\mathrm{pH}$ and particle size distributions proceed over time. During the experiments, the mixing of solutions and the $\mathrm{pH}$ measurements are carried out under forced convection condition $(1750 \mathrm{rpm})$ and ultrasonication intensity of $30 \%$ in order to prevent particles agglomeration and presence of bubbles in the optical path of the laser beam.

\section{NUMERICAL SIMULATIONS}

In order to simulate the precipitation of calcium carbonate in concentrated electrolyte solutions, eqns (2)-(5) together with eqns (6) and (13) are numerically solved for the variables $a_{1}^{\mathrm{Na}_{2} \mathrm{Co}_{3}}(\mathrm{x}, t), \alpha_{1}^{\mathrm{CaCl}_{2}}(\mathrm{x}, t), \alpha_{2}(\mathrm{x}, t), \mathrm{v}_{1}(\mathrm{x}, t), \mathrm{v}_{2}(\mathrm{x}, t)$, and $\varphi_{i}(\mathrm{x}, t)$ with $i=0, \ldots, 4$ and ratio factor 8 , by assuming the same conditions found in the volumetric precipitation experiments previously reported. In this case, one employs the below initial mass fractions,

$$
\alpha_{1}^{\mathrm{Na}_{2} \mathrm{CO}_{3}}(\mathrm{x}, 0)=0.001, \quad \alpha_{1}^{\mathrm{CaCl}_{2}}(\mathrm{x}, 0)=0.199, \quad \alpha_{1}^{\mathrm{NaCl}}(\mathrm{x}, 0)=0.800,
$$

and the physical parameters given in Table 1, where the density and dynamic viscosity of the solution are obtained by the volume weighted mixing law and mass weighted mixing law, respectively.

Table 1: Physical quantities employed in the numerical simulations.

\begin{tabular}{lll}
\hline Physical quantity & Symbol & Value \\
\hline Density of liquid phase & $\rho_{1}$ & $1106.91 \mathrm{~kg} \mathrm{~m}^{-3}$ \\
Viscosity of liquid phase & $\mu_{1}$ & $0.0013388 \mathrm{~Pa} \mathrm{~s}^{-1}$ \\
Density of calcite & $\rho_{2}$ & $2711.00 \mathrm{~kg} \mathrm{~m}^{-3}$ \\
Restitution coefficient of particle collisions & $e_{22}$ & 0.90 \\
Maximum random close packing & $a_{2, \text { max }}$ & 0.62 \\
Surface energy & $\sigma$ & $0.068 \mathrm{~N} \mathrm{~m}^{-1}$ \\
Geometrical shape factor & $\beta$ & 16.76 \\
Molecular volume of calcium carbonate & $\vartheta$ & $6.132 \times 10^{-29} \mathrm{~m}^{3}$ \\
Diffusion coefficient for calcium carbonate & $D$ & $8.67 \times 10^{-10} \mathrm{~m}^{2} \mathrm{~s}^{-1}$ \\
Interionic distance between Ca ${ }^{2+}(\mathrm{aq})$ and $\mathrm{CO}_{3}^{2-}(\mathrm{aq})$ & $\delta$ & $7.62 \times 10^{-10} \mathrm{~m}^{-3}$ \\
Ionic strength & $I$ & $4980 \mathrm{~mol} \mathrm{~m}^{-3}$ \\
Absolute temperature & $T$ & $298.15 \mathrm{~K}^{2}$ \\
\hline
\end{tabular}




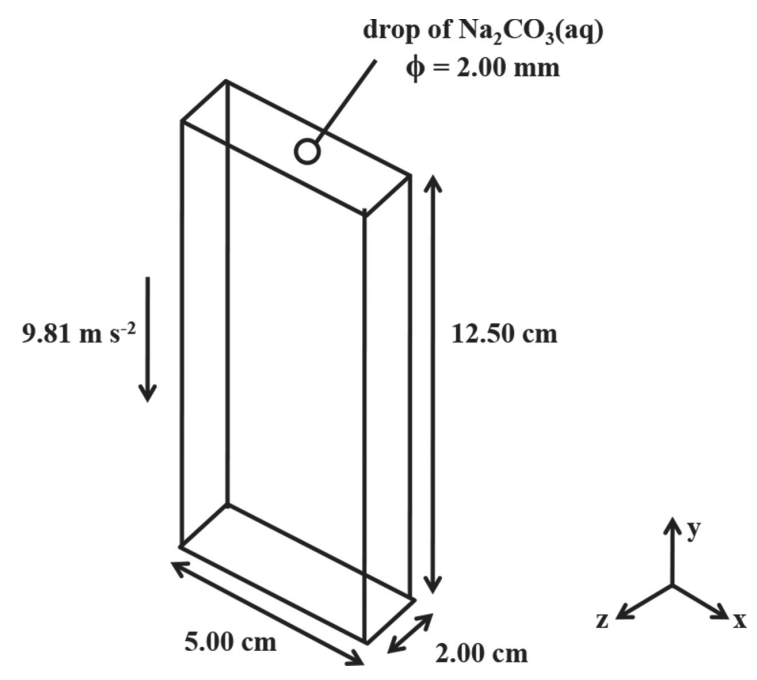

Figure 1: 3D computational domain. A vessel of $134.50 \mathrm{~cm}^{3}$ initially contains a mixture of $\mathrm{NaCl}(\mathrm{aq}), \mathrm{CaCl}_{2}(\mathrm{aq})$, and $\mathrm{Na}_{2} \mathrm{CO}_{3}(\mathrm{aq})$. At time $t=0 \mathrm{~s}$, a drop of sodium carbonate solution with dimensions of $2.00 \mathrm{~mm}$ is added to the mixture of $\mathrm{NaCl}(\mathrm{aq}), \mathrm{CaCl}_{2}(\mathrm{aq})$ and $\mathrm{Na}_{2} \mathrm{CO}_{3}(\mathrm{aq})$. The drop introduces a perturbation into the system, leading to the onset of calcium carbonate precipitation.

The numerical simulations are restricted to $228 \mathrm{~s}$ from the instant at which precipitation of calcium carbonate starts. During this time range, the phenomena of coalescence and particles aggregation are absent and, consequently, the phenomenon of Ostwald ripening may be neglected. In addition, the solid phase is only formed by particles of the allotropic form calcite whose diameters range from $0.500 \mathrm{~nm}$ to $2048 \mathrm{~nm}$. To close the formulation of the problem, it is also imposed that both solid and liquid phases have zero velocity (no-slip condition) in relation to the stationary walls of the dispensing unit of the particle size analyzer, and the specularity coefficient between the walls and the solid particles is defined as zero. Indeed, temperature is assumed to be uniform in the solid-liquid mixture, and a laminar fluid flow regime is considered throughout the simulations.

All numerical simulations are performed with a phase coupled SIMPLE scheme (Semi-Implicit Method for Pressure Linked Equations) [13] available in the software ANSYS/Fluent 16.2 [14], a commercial computational fluid dynamics software based on the finite volume method. A regular mesh of 134500 hexahedron elements with dimensions of $1.00 \mathrm{~mm}$ is constructed over a rectangular parallelepiped of volume of $134.50 \mathrm{~cm}^{3}$, which represents the dispensing unit where the experiment is carried out (Fig. 1). During the simulations, first-order upwind schemes for spatial and temporal discretizations are used, and the absolute convergence criterion is determined in 0.001 . The time step size is stipulated in $0.08 \mathrm{~s}$, and numerical convergence is usually reached after 30 iterations.

\section{MODEL VALIDATION AND NUMERICAL RESULTS}

In this work, for the sake of brevity, model validation is performed by using measurements of $\mathrm{pH}$ and growth rate of particles. Evidently, model validation can be also made through 


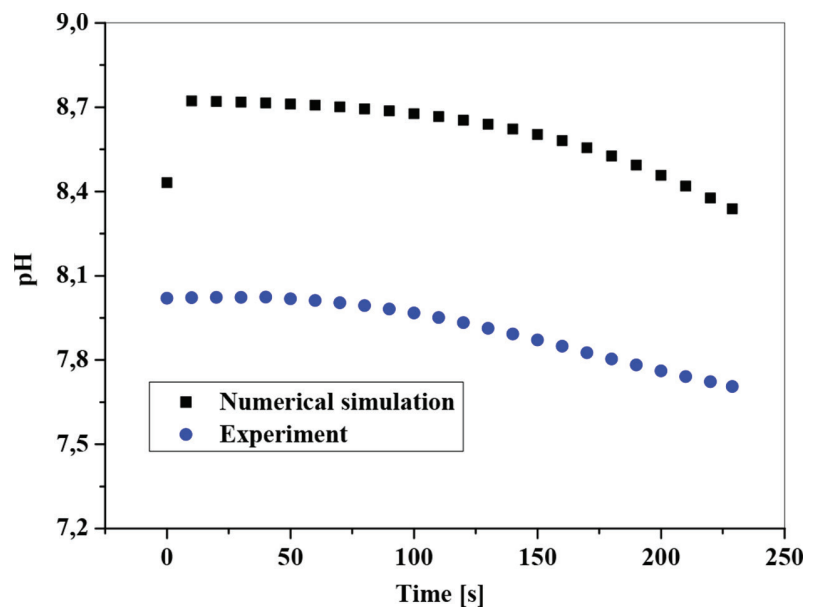

Figure 2: Comparison between theoretical and experimental results for temporal variation of $\mathrm{pH}$.

comparison of the experimental particles size distribution curve with the theoretical one. Such results are found in [15].

Figure 2 shows the temporal changes of $\mathrm{pH}$ observed during the volumetric precipitation experiment. According to Fig. 2, one observes that the theoretical results are consistent with the experimental ones, and they reproduce the tendency of $\mathrm{pH}$ variation during the chemical reaction. In fact, the quantitative differences observed between the theoretical values and the experimental ones may be attributed to the technical limitations of $\mathrm{pH}$ electrodes to provide instantaneous measurements. As pointed out by Sousa et al. [16], changes of pH during volumetric precipitation experiments are faster than the time required by the electrode to reach equilibrium with the solution. Consequently, there will always be a detectable lag in the $\mathrm{pH}$ measurements.

In turn, Fig. 3 presents the growth rate of particles observed during the volumetric precipitation experiment. Again the proposed two-fluid model reproduces the experimental tendency observed for the growth rate of particles. Moreover, one also verifies that the growth rate of particles changes during the chemical reaction, so that calcium carbonate crystals initially grow at a higher rate and later this rate decreases. This occurs because at the beginning of the precipitation there is a large amount of free $\mathrm{Ca}^{2+}(\mathrm{aq})$ and $\mathrm{CO}_{3}^{2-}(\mathrm{aq})$ ions in solution. However, as the chemical reaction proceeds, the concentration of $\mathrm{Ca}^{2+}(\mathrm{aq})$ and $\mathrm{CO}_{3}^{2-}(\mathrm{aq})$ in solution decreases, as well as the growth rate of crystals. As a consequence, the particles growth is no longer determined by the concentration of dissolved ions, but rather by the diffusion rate.

Once the proposed model has been validated, one may exploit the numerical simulations to acquire further information about calcium carbonate precipitation in concentrated electrolyte solutions. In this context, it is interesting to analyze the evolution of supersaturation ratio during the volumetric precipitation experiment since the theoretical tools available to chemists and chemical engineers cannot predict the temporal evolution of supersaturation ratio during a precipitation chemical reaction. This shows the relevance that the proposed two-fluid model could have for those researchers interested in processes of crystallization. 


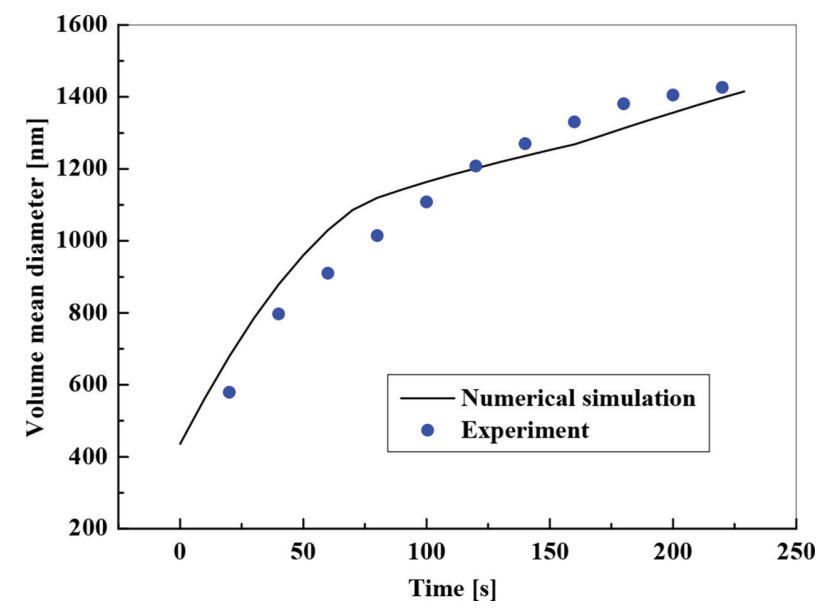

Figure 3: Comparison between theoretical and experimental results for growth of calcium carbonate crystals during the precipitation chemical reaction.

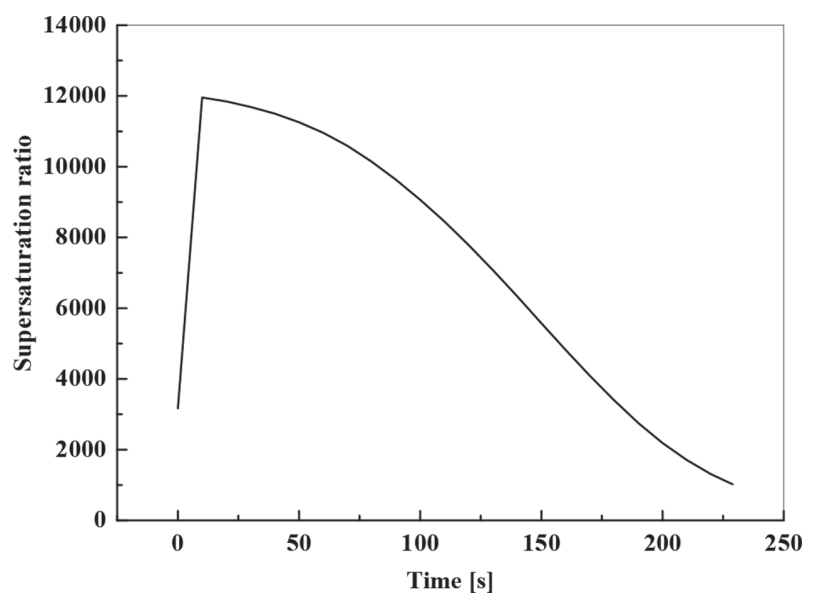

Figure 4: Variation of supersaturation ratio of a supersaturated solution of calcium carbonate during a volumetric precipitation experiment. Results obtained from the numerical simulations.

Precipitation of calcium carbonate in concentrated electrolyte solutions is a phenomenon governed by the system supersaturation, which can be estimated in terms of the ratio between the actual concentration of $\mathrm{CO}_{3}^{2-}(\mathrm{aq})$ and $\mathrm{Ca}^{2+}(\mathrm{aq})$ ions in solution and that expected for the solution at equilibrium. Then, since a supersaturated solution has a greater concentration of dissolved ions than would exist at equilibrium, such a ratio will always be a number greater than unity. Figure 4 shows the evolution of the supersaturation ratio during $\mathrm{CaCO}_{3}$ (s) precipitation. According to Fig. 4, one notices that the supersaturation ratio initially reaches a maximum value, which decreases over time. This indicates that the system is initially far from the equilibrium and as calcium carbonate precipitates, the system evolves towards the equilibrium state. 
Furthermore, from Fig. 4 one may gain a phenomenological insight into the process of calcium carbonate precipitation. During the volumetric precipitation experiment, supersaturation ratio reaches its maximum value precisely at the critical point, where the solution $\mathrm{pH}$ is maximum. At this point, there is no longer accumulation of ions in solution, and $\mathrm{CO}_{3}^{2-}(\mathrm{aq})$ and $\mathrm{Ca}^{2+}(\mathrm{aq})$ spontaneously react to form stable nuclei of calcium carbonate, characterizing the onset of $\mathrm{CaCO}_{3}(\mathrm{~s})$ precipitation. Therefore, while solution of $\mathrm{Na}_{2} \mathrm{CO}_{3}(\mathrm{aq})$ is added to the mixture of $\mathrm{NaCl}(\mathrm{aq})$ and $\mathrm{CaCl}_{2}(\mathrm{aq})$ during the volumetric precipitation experiment, nucleation of $\mathrm{CaCO}_{3}(\mathrm{~s})$ is not spontaneous.

As described in [15], from the numerical simulations one may also obtain valuable information about the temporal and spatial evolution of the reaction rate during the volumetric precipitation experiment. Figure 5 shows the reaction rate observed from the instant at which the system reaches its maximum supersaturation ratio. As the last drop of sodium carbonate falls into the electrolyte solution, the reaction rate changes according to the dynamics of the drop. Initially, the concentration of $\mathrm{CO}_{3}^{2-}(\mathrm{aq})$ and $\mathrm{Ca}^{2+}(\mathrm{aq})$ ions is equal at all points of the solution, as well as the reaction rate. Then, as the drop deforms and breaks up during the falling, high-velocity laminar flow zones are especially formed in the centerline of the vessel, where there is an instantaneous accumulation of dilute sodium carbonate solution. As a result, the aggregation of ions to form a critical nucleus becomes more difficult, leading to a decrease of the reaction rate in the central zones. Therefore, the last drop of sodium carbonate added

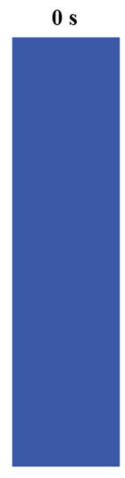

$120 \mathrm{~s}$

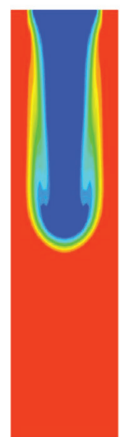

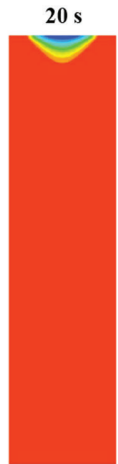

$140 \mathrm{~s}$

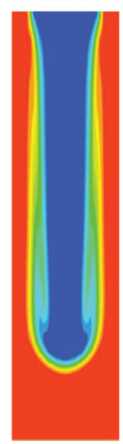

$40 \mathrm{~s}$

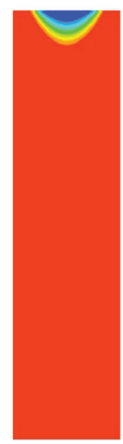

$160 \mathrm{~s}$

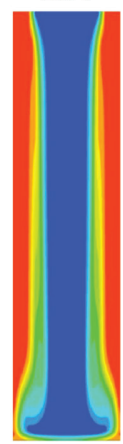

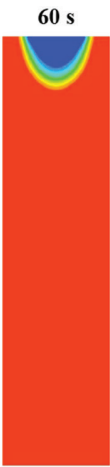

$180 \mathrm{~s}$

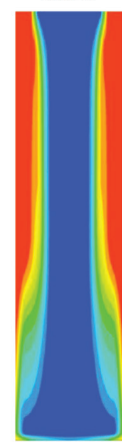

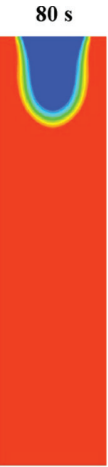

$200 \mathrm{~s}$

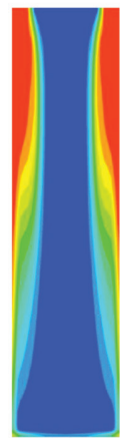

$100 \mathrm{~s}$

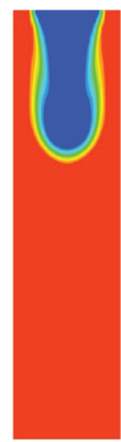

$220 \mathrm{~s}$

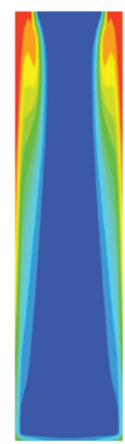

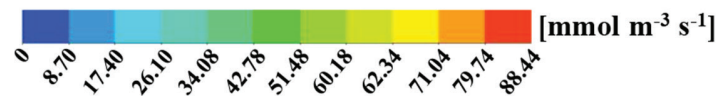

Figure 5: Contour graphs for the reaction rate during the volumetric precipitation experiment. 
to the concentrated electrolyte solution not only introduces a chemical perturbation into the system that initiates the precipitation of calcium carbonate, but also a mechanical perturbation that disturbs the kinetics of the precipitation chemical reaction.

\section{REFERENCES}

[1] Zhong, S. \& Mucci, A., Calcite and aragonite precipitation from seawater solutions of various salinities: Precipitation rates and overgrowth compositions. Chemical Geology, 78(3-4), pp. 283-299, 1989. https://doi.org/10.1016/0009-2541(89)90064-8

[2] Zuddas, P. \& Mucci, A., Kinetics of calcite precipitation from seawater: I. A classical chemical kinetics description for strong electrolyte solutions. Geochimica et Cosmochimica Acta, 58(20), pp. 4353-4362, 1994.

https://doi.org/10.1016/0016-7037(94)90339-5

[3] Lin, Y-P., Singer, P.C. \& Aiken, G.R., Inhibition of calcite precipitation by natural organic material: Kinetics, mechanisms, and thermodynamics. Environmental Science and Technology, 39(17), pp. 6420-6428, 2005.

https://doi.org/10.1021/es050470z

[4] Sousa, M.F.B. \& Bertran, C.A., New methodology based on static light scattering measurements for evaluation of inhibitors for in bulk $\mathrm{CaCO}_{3}$ crystallization. Journal of Colloid and Interface Science, 420(15), pp. 57-64, 2014.

https://doi.org/10.1016/j.jcis.2014.01.001

[5] Freeman, C.L., Harding, J.H. \& Duffy, D.M., Simulations of calcite crystallization on self-assembled monolayers. Langmuir, 24(17), pp. 9607-9615, 2008. https://doi.org/10.1021/la800389g

[6] Yan, Y. \& Chen, C-C., Thermodynamic modeling of $\mathrm{CO}_{2}$ solubility in aqueous solutions of $\mathrm{NaCl}$ and $\mathrm{Na}_{2} \mathrm{SO}_{4}$. The Journal of Supercritical Fluids, 55(2), pp. 623-634, 2010. https://doi.org/10.1016/j.supflu.2010.09.039

[7] Reis, M.C. \& Wang, Y., A two-fluid model for reactive dilute solid-liquid mixtures with phase changes. Continuum Mechanics and Thermodynamics, 29(2), pp. 509-534, 2017. https://doi.org/10.1007/s00161-016-0546-6

[8] Ramkrishna, D., Population Balances: Theory and Applications to Particulate Systems in Engineering, Academic Press: San Diego, 2000.

[9] Hounslow, M.J., Ryal, R.L. \& Marshall, V.R., A discretized population balance for nucleation, growth, and aggregation. AIChE Journal, 34(11), pp. 1821-1832, 1988. https://doi.org/10.1002/aic.690341108

[10] Nielsen, A.E., Kinetics of Precipitation, Pergamon: Oxford, 1964.

[11] Brečević, L. \& Kralj, D., On calcium carbonates: from fundamental research to application. Croatica Chimica Acta, 80(3-4), pp. 467-484, 2007.

[12] Syamlal, M., The particle-particle drag term in a multiparticle model of fluidization, May 1987, EG \& G Washington Analytical Service Center, Morgantown, USA.

[13] Patankar, S.V. \& Spalding, D.B., A calculation procedure for heat, mass and momentum transfer in three-dimensional parabolic flows. International Journal of Heat and Mass Transfer, 15(10), pp. 1787-1806, 1972. https://doi.org/10.1016/0017-9310(72)90054-3

[14] ANSYS, Inc., ANSYS/Fluent ${ }^{\circledR}$ Release 16.2, Canonsburg, USA, 2015. 
[15] Reis, M.C., Sousa, M.F.B., Alobaid, F., Bertran, C.A. \& Wang, Y., A two-fluid model for calcium carbonate precipitation in highly supersaturated solutions. Advanced Powder Technology, submitted for publication, 2017.

[16] Sousa, M.F.B., Signorelli, F. \& Bertran, C.A., Fast evaluation of inhibitors for calcium carbonate scale based on $\mathrm{pH}$ continuous measurements in jar test at high salinity condition. Journal of Petroleum Science and Engineering, 147, pp. 468-473, 2016.

https://doi.org/10.1016/j.petrol.2016.09.007 